\title{
EL CRISTO DE UXMAL: HISTORIA, CELEBRACIÓN Y CONFLICTO DE UNA FIESTA PATRONAL EN EL PÚ'UK
}

\author{
Iván Solís SosA \\ Centro INAH-Yucatán
}

Resumen: Los enfrentamientos entre los integrantes de los Partidos Socialista del Sureste y Liberal fueron constantes durante la Revolución mexicana en Yucatán. Numerosos pueblos, alentados por el primero de los partidos políticos, desafiaron abiertamente a las clases dominantes de sus lugares. En Muna, al sur del estado de Yucatán, se celebraba anualmente, durante el mes de mayo, al Cristo de Uxmal; en 1919, sin embargo, hubo una fuerte oposición entre estos dos segmentos de la población para que se llevara a cabo la fiesta patronal. Aunque el conflicto tuvo un matiz religioso, fue motivado por cuestiones políticas, étnicas y de clase, en un intento por reivindicar a los campesinos mayas. La magnitud de estos sucesos marcó un parteaguas en la historia local y regional en las siguientes décadas, llegando incluso hasta nuestros días.

Palabras clave: Cristo de Uxmal, socialistas y liberales, fiesta patronal, conflictos interétnicos.

ABSTRACT: Confrontations amongst members from the Socialista del Sureste and Liberal parties were recurrent during the Mexican Revolution in Yucatan. Numerous towns, encouraged by the former political party, defied the elite class of their towns. In Muna, situated to the south of Yucatán state, the Christ of Uxmal was celebrated annually during May. In 1919, however, there was a strong opposition to this patronage festival between the two aforementioned segments of the population. Although the conflict had a religious hint, it was rather motivated by political, ethnic and classist issues in an attempt to reinstate Mayans countrymen to their town. The magnitude of these outcomes set a precedent in the local and regional history for the forthcoming decades which is still prevalent these days.

Kerwords: Cristo de Uxmal, socialists and liberals, saint patron's holiday, interethnic conflict.

RECEPCIÓN: 17 de agosto de 2011.

ACEPTACIÓN: 24 de abril de 2012. 



\title{
EL CRISTO DE UXMAL: HISTORIA, CELEBRACIÓN Y CONFLICTO DE UNA FIESTA PATRONAL EN EL PÚ'UK ${ }^{1}$
}

\author{
Iván Solís SosA \\ Centro INAH-Yucatán
}

El presente trabajo tiene por objetivo analizar un conflicto político-religioso ocurrido en Muna, población enclavada en la zona pu'uk, al sur del estado de Yucatán, y que involucró a dos sectores de la población, representados por dos partidos políticos antagónicos: el Partido Socialista del Sureste y el Partido Liberal Yucateco. Los enfrentamientos entre los integrantes de estas agrupaciones políticas fueron constantes durante los años más álgidos de la Revolución mexicana en Yucatán, alentados especialmente por el Partido Socialista del Sureste (Manzanilla, 1921; Domínguez, 1979; Paoli y Montalvo, 1980; Joseph, 1992; Mantilla, 2003).

Este partido adquirió considerable fuerza a partir de que Felipe Carrillo Puerto lo dirigiera en el año de 1917 (Domínguez, 1979; Paoli y Montalvo, 1980; Joseph, 1992; Mantilla, 2003) e iniciara la labor de organizar a los campesinos, jornaleros y obreros en las llamadas "Ligas de Resistencia" en cada una de las poblaciones de Yucatán (Campeche y Quintana Roo). Dichas "ligas" eran las células de una organización mayor denominada "Liga Central de Resistencia", dependiente del Partido Socialista, con sede en Mérida, Yucatán² (Bustillos, 1959; Joseph, 1992; Mantilla, 2003).

\footnotetext{
${ }^{1}$ Ponencia presentada originalmente con el título "Los Sucesos de Muna de 1919. Un episodio de la Revolución mexicana en Yucatán" en el Octavo Congreso Internacional de Mayistas, México, D. F. del 8 al 13 de agosto de 2010. La recopilación de la información hemerográfica y de archivo de la cual se nutre este trabajo se realizó, en buena medida, en el marco del Proyecto Etnografía de las Regiones Indígenas de México en el Nuevo Milenio, auspiciado por el CONACYT-INAH en la línea de investigación denominada "Sistemas Normativos y Nuevas Alternativas Religiosas", y coordinado por Elio Masferrer, Ella F. Quintal y Lourdes Báez. El pu'uk es la región situada en el sur del estado de Yucatán y se caracteriza por ser en una cordillera de baja altura (su punto más alto apenas rebasa los 300 metros en Tekax) compuesta principalmente de roca calcárea

${ }^{2}$ El antecedente inmediato de este partido fue el Partido Socialista Obrero (PSO) fundado en junio de 1916, a instancias del gobernador y comandante militar general Salvador Alvarado. Este partido fue integrado por los sindicatos obreros afiliados a la Casa del Obrero Mundial, fundada por el mismo general el 18 de mayo de 1915; según Mantilla (2003: 31-32), el Partido Socialista Obrero surgió por la intención de Alvarado de "controlar todos los espacios de administración pública y en la coyuntura electoral. Fue un partido eminentemente obrero que se organizó en comités y subcomités. Anterior al PSO había funcionado el Gran Partido Obrero Reformista, fundado en agosto de 1914 por Héctor Victoria, Diego Rendón, Miguel Cantón y Anatolio B. Buenfil; desapareció en 1916 y sus pocos miembros se integraron al Partido Socialista Obrero. Posteriormente se le nombró "Partido Socialista Yucateco" y fue el antecedente inmediato del Partido Socialista del Sureste (Bustillos, 1959; Domínguez, 1979; Paoli y Montalvo, 1980; Medina, 1991; Joseph, 1992; Mantilla, 2003).
} 
Pasemos ahora a expresar los elementos que integran el concepto de ligas de resistencia. Según Paoli y Montalvo (1980: 102-103), el nombre de liga tiene un "sabor insurreccional”, de agitación, que mucho refiere a la práctica política europea, francesa para ser exactos, del siglo pasado. Siguiendo a Duverger, Paoli y Montalvo indican que el caso de la experiencia francesa no se repite en Yucatán debido a que en ese país las ligas "eran máquinas de agitación y propaganda, no presentaban candidatos a las elecciones; las ligas eran violentamente antiparlamentarias" porque se negaban a jugar el juego democrático.

Los mismos autores apuntan que

[l]as ligas son unidades con una organización cada vez más disciplinada y con articulación centralizada que, entre sus muchas actividades, realizan trabajos electorales. Sin embargo, es curioso aceptar que así como en el terreno doctrinario, el Partido [socialista] recibió muchas tardías influencias del socialismo utópico y del anarquismo, en el terreno de la organización, adoptó el nombre de liga, que alude a un pasado en el que todavía no hacían su aparición los partidos políticos [...] (Paoli y Montalvo, 1980: 102).

Y sobre la "resistencia", dicen que las "ligas" aluden al trabajo fundamentalmente reivindicativo, a su lucha económica y social. Además de que fueron organizaciones promotoras de conciencia de clase, de conciencia política, y su éxito se debió, en parte, a que las ligas en Yucatán partieron de un nivel bajo de conciencia y fueron incrementándolo hasta alcanzar manifestaciones muy considerables de lucha de clases en los campos y en las ciudades (Paoli y Montalvo, 1980: 103), como puede verse en la documentación generada en esa época y que da cuenta de esta situación.

Por otra parte, Joseph, citando a Carrillo Puerto, dice que las "ligas" vinieron a resolver algunos de los múltiples problemas que existían en el campo yucateco porque ellas

[...] trabajarían, con la asistencia del gobierno, para resolver los apremiantes problemas sociales de la vida del campo, tales como los salarios y las condiciones de trabajo, el acceso a las milpas y la recuperación de las antiguas tierras aldeanas, y el recrudecimiento de los abusos de los jefes locales [...] (Joseph, 1992: 144).

Es posible que el Partido Socialista del Sureste, aparejado con sus postulados y principios de igualdad y justicia social, así como con una campaña institucional de afiliación, llevara a que la gran mayoría de la población maya yucateca simpatizara desde un principio con sus premisas y que se afiliara a él. El Partido Liberal, por su parte, agrupaba principalmente a la mayoría de los comerciantes, pequeños propietarios, hacendados, burócratas, profesionistas, campesinos, etcétera, tanto de la capital como de las principales poblaciones del estado. Según Domínguez (1979: 157), los sectores conservadores de la sociedad yucateca encontraron en este partido un baluarte desde el cual poder defender sus intereses. En Muna, Yaxcabá, Sotuta y otras poblaciones de Yucatán, los liberales 
tenían los hilos del comercio, el poder, la ley, los impuestos, el aguardiente y las comunicaciones (Domínguez, 1979: 168-169).

En la gran mayoría de las poblaciones yucatecas fue conformada una "liga de resistencia”, la cual agrupó principalmente a los trabajadores mayas, a los mestizos y a algunos comerciantes del lugar. Con el liderazgo de Carrillo Puerto, las ligas adquirieron una considerable fuerza política y una sólida organización, de tal suerte que en todo México era considerada una de las fuerzas políticas mejor organizadas, si no es que la mejor. Es por eso que Bustillos menciona que desde entonces

[...] el indio tuvo que luchar contra el capitalismo, la fuerza organizada del trabajo. No fue ya posible que las haciendas continuasen siendo encomiendas mal encubiertas, en las que los peones desempeñaban función de máquinas humanas sujetas al mayor rendimiento en provecho del propietario blanco o mestizo y alimentados con un puñado de maíz. Por primera vez en la historia de Yucatán, el indio entraba como factor verdaderamente libre a discutir el precio de su salario y a reclamar su parte de utilidades [...] (Bustillos, 1959: 210)

A continuación presentaré una serie de enfrentamientos entre los "socialistas" y los "liberales", motivados por razones más bien políticas que religiosas, ocurridos en Muna, a partir del mes de mayo de 1919, con motivo del robo del Cristo de Uxmal de la iglesia católica del lugar; aunque el matiz religioso estuvo presente en buena parte del conflicto, parece ser que fue usado como una suerte de pretexto por parte de ambos bandos para dirimir sus diferencias. ${ }^{3}$

Primero haré una contextualización de los espacios y lugares donde tuvieron lugar los llamados "sucesos", posteriormente abordaré los conflictos en detalle para ver más de cerca las características que tomaron y los actores que tuvieron una destacada participación, y por último daré una interpretación de lo acontecido vinculando el fenómeno con cuestiones de tipo político - traducido como la lucha por el poder político-y con cuestiones étnicas y de clase.

\section{El Cristo de la hacienda Uxmal}

La hacienda Uxmal tiene una larga historia. El famoso viajero norteamericano John Lloyd Stephens nos da las primeras noticias detalladas de ella, él mismo tuvo en sus manos los documentos de fundación originales proporcionados por el entonces propietario de la hacienda en los años cuarenta del siglo xIx, don Simón Peón. De dichos papeles Stephens extrajo algunos datos históricos, mis-

\footnotetext{
${ }^{3}$ Quintal, et. al. (en prensa) analizaron el conflicto ocurrido en Muna más bien como un enfrentamiento religioso entre católicos y presbiterianos, pero ampliamente motivado por luchas de carácter político; Mantilla (2003) afirma que el conflicto se debió a cuestiones políticas derivadas en buena medida de la división existente entre los simpatizantes del candidato a la presidencia de la República, Álvaro Obregón, y los simpatizantes del ingeniero Bonillas.
} 
mos que plasmó posteriormente en su obra titulada Incidentes de viaje a Yucatán (1843). En este libro apunta que la hacienda Uxmal fue fundada a finales del siglo XVII por Lorenzo de Evia, a la sazón regidor del Ayuntamiento de Mérida, a quien el gobierno español de esos años le concedió una merced real de cuatro leguas de terreno "desde los edificios de Uxmal hacia el sur, una al oriente, otra al poniente y otra al norte [...] incultos y realengos que no podían aprovechar los indios para sus siembras y labores, sirviendo únicamente para la cría de ganado vacuno". Además de lo anterior, dicho regidor argumentó, a fin de justificar su petición ante la autoridad real que

[...] deseaba poblar aquellos terrenos de ganado vacuno, pidiendo en consecuencia se le diesen, con tal objeto y en nombre de su majestad, toda vez que no resultaba perjuicio de tercero, sino al contrario, un gran servicio a Dios, nuestro señor, porque dicho establecimiento evitaría que los indios diesen culto al diablo en los edificios viejos que había en aquel sitio, teniendo en ellos sus ídolos a los cuales quemaban copal y hacían otros detestables sacrificios, según lo verificaban diariamente, como era público y sabido... (Stephens, 1984: T. 1, 284).

Sobre el origen de la imagen del Cristo no tenemos datos históricos fidedignos que lo sustenten. Sin embargo, Bustillos (s.f.: 26) sugiere que data de la segunda mitad del siglo xviı. Según este autor, el nombre del santo se le atribuyó a fray Diego López de Cogolludo, quien residió en el convento de Muna en esos años y, en una de las visitas hechas a las ruinas de Uxmal, encontró allí ofrendas e ídolos del dios Chaac hechas recientemente por los pobladores de la región. El fraile destruyó todo cuanto allí había y se propuso evangelizar a los idólatras mediante la adoración y la fe en Cristo, cuya imagen "hizo labrar precisamente en Uxmal" y "en una nutrida peregrinación fue conducida a la iglesia de Muna, en su ataúd de cristal" (Bustillos, s.f.: 26).

Por otro lado, hacia fines del siglo xVIII o principios del xIx, la hacienda Uxmal pasó a ser propiedad de la familia Peón en una línea de sucesión hereditaria que fue de padres a hijos hasta bien entrado el siglo xx, cuando tuvieron lugar los llamados "sucesos" de Muna de 1919.

El Cristo o Señor de Uxmal fue una imagen reverenciada por un considerable número de devotos en la comarca desde, por lo menos, la primera mitad del siglo XIX. El mismo Stephens, en la descripción que hace de la hacienda Uxmal en 1840, da cuenta de la existencia de una capilla con una imagen, a la cual se refiere así: "Uxmal tiene también su capilla en que se venera la imagen de nuestro señor, que es muy reverenciada por los indios de las haciendas circunvecinas, y cuya fama había llegado hasta los criados de la casa [de la familia Peón] en Mérida, pues fue el primer objeto que llamó la atención de nuestro guía” (Stephens, 1984: T. 1, 10).

No hemos encontrado datos posteriores a este último que den cuenta del fervor religioso hacia la imagen de Uxmal; sin embargo, a raíz de los sucesos de 1919, en sus declaraciones, algunos de los involucrados, mayores de 50 años, dijeron tener recuerdos de que desde niños eran llevados por sus padres hasta la 
hacienda Uxmal, lugar desde donde era tomada la imagen y llevada en procesión a Muna para sus festejos. Es decir que esta práctica data desde, por lo menos, el último cuarto del siglo xIx (figura 1)

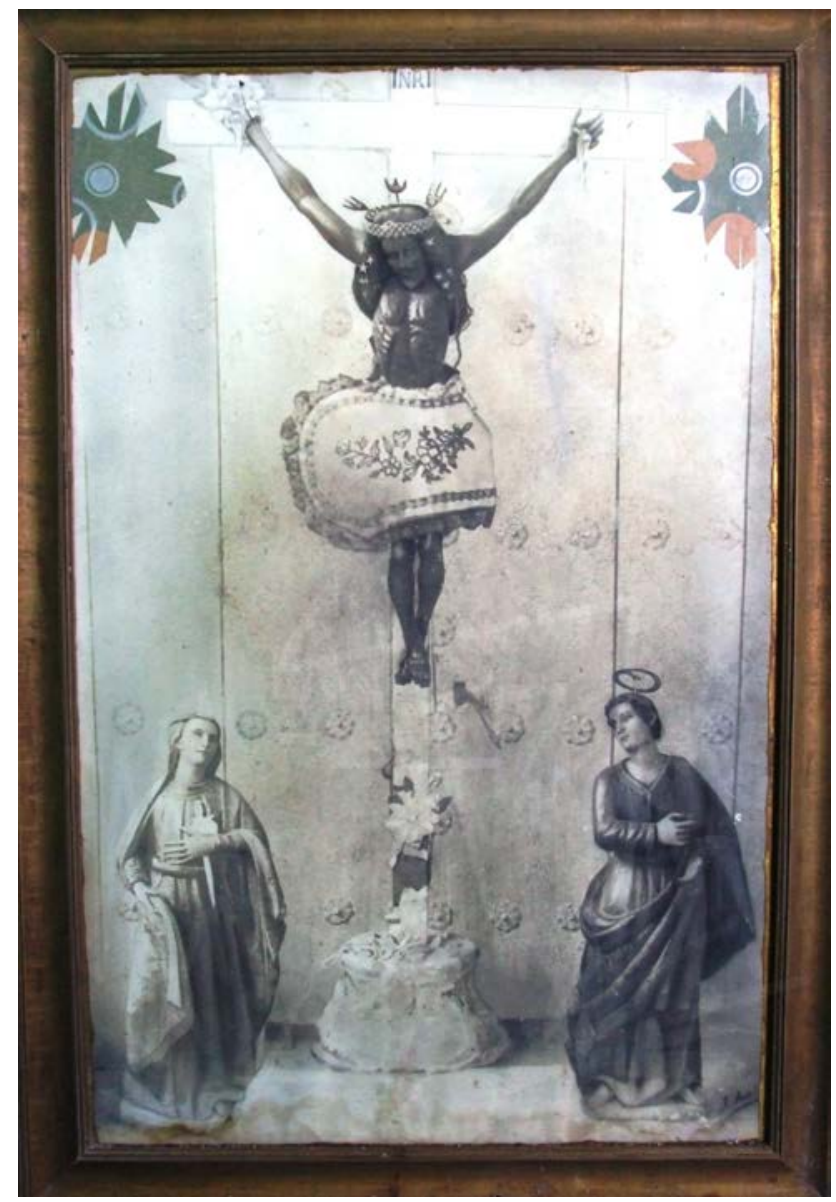

Figura 1. El Cristo de Uxmal, la Dolorosa y San Juan.

Cuadro localizado al interior de la capilla de San Bernardo en el barrio del mismo nombre en Muna, Yucatán.

\section{Muna y la fiesta patronal en honor al Cristo de Uxmal}

En 1910, Muna era una población biétnica de 4946 habitantes (Rodríguez Losa, 1977) distribuidos en la cabecera y en las cerca de 20 haciendas, sitios y parajes de su municipio. Como otras poblaciones de Yucatán, se conformaba predominantemente de mayas y de un reducido grupo de mestizos o no mayas. La gran mayoría de los habitantes se dedicaba a las labores agrícolas tanto en las 
haciendas henequeneras y ganaderas de los alrededores como en los montes no ocupados por estas propiedades.

En la plaza principal del pueblo o "el centro" vivían exclusivamente la gente "visible", los ts'ules (los tenderos, comerciantes, los de apellido español), los cuales fungían como autoridades locales y patrones de numerosos habitantes del lugar. Eran los organizadores de las fiestas del pueblo: el carnaval, las fiestas patronales y las fiestas cívicas.

Dentro de dicho contexto, eran estos miembros de la élite local los que cada año, por lo menos desde fines del siglo xix, y en el inicio de la Semana Santa (lunes santo), organizaban las actividades para festejar al santo patrón del pueblo, ${ }^{4}$ el Cristo o Señor de Uxmal, imagen llevada en procesión desde la hacienda del mismo nombre hasta la iglesia parroquial de Muna, la cabecera municipal.

Una vez concluida la Semana Santa, seguía el novenario a principios del mes de mayo; posteriormente, a fines de este mes, eran organizadas en el barrio de San Bernardo corridas de toros, vaquerías, peleas de gallos, misas, novenarios, venta de aguardiente, etcétera. Concluidos los festejos, el santo Cristo era regresado a la capilla de la hacienda Uxmal.

Durante los años del gobierno del general Salvador Alvarado (1915-1918), este tipo de festividades fueron suspendidas y varias fueron las manifestaciones iconoclastas, de manera que, cuando éstas pudieron reanudarse, las fiestas tradicionales fueron retomadas con "inusitado entusiasmo", como sucedió con la fiesta de Muna. ${ }^{5}$

Después de haberse verificado por muchos años, en el año de 1919, hubo una fuerte oposición por parte de algunos miembros del Partido Socialista, así como de algunos integrantes de la iglesia presbiteriana, para que dicha fiesta se llevara a cabo. Ambos grupos argumentaron que con la celebración sólo iban a beneficiarse unos cuantos comerciantes, a la sazón organizadores de los festejos: Serapio Cabrera, Manuel y Sóstenes Carrillo, Delio Lara y Enrique Cáceres. ${ }^{6}$

Fuentes históricas escritas, así como la historia oral de Muna, refieren que las acciones de oposición y enfrentamientos entre los grupos políticos se debieron,

\footnotetext{
${ }^{4}$ Según Gerhard (1991: 101), cuando fue fundado el convento de Muna en 1609 tuvo por advocación a San Juan Evangelista; más tarde, sin especificar el año, tuvo la advocación de la Asunción, posiblemente a raíz de la fundación de la cofradía de Maxal en 1741 (Suárez, 2002) o quizá antes de esta fecha. Sin embargo, desde por lo menos la segunda mitad del siglo xix parece haber surgido el culto al Cristo de Uxmal, compitiendo o relegando a segundo término a la virgen de la Asunción. Las fiestas en honor al Cristo eran más vistosas y elaboradas que las que se le hacían a la Asunción, que básicamente consistían en misas, rosarios y novenarios.

${ }^{5}$ Sobre el tema de las acciones en contra de la iglesia católica en Mérida, véase Negroe, 2007: 63-103.

${ }^{6}$ Existía una abierta oposición para la realización de las fiestas de los pueblos; por ejemplo, en la asamblea socialista del lunes 10 de marzo de 1919 se trató, entre otros asuntos, lo referente a este tema. Al respecto, Liborio Blanco mencionó que estas fiestas se hacían con el pretexto de recaudar fondos para mejoras materiales y que "en ellas hay juego, corrida de toros, cantinas y diversiones deshonestas, que los explotadores sin conciencia, conociendo el lado flaco del pueblo, se valen de esa debilidad para comerciar inicuamente, pues hasta hoy, con honrosas excepciones, no se han efectuado tales mejoras en los pueblos", en: “Notas Socialistas", La Revista de Yucatán, Mérida, Yucatán, 13 de marzo de 1919.
} 
en buena medida, a las desavenencias personales entre dos personajes pertenecientes a cada uno de los bandos: por un lado, Manuel Carrillo, miembro de la élite local de Muna y uno de los principales representantes del Partido Liberal, y, por el otro, Liborio Blanco, oriundo de Ticul y avecindado en Muna desde hacía varios años atrás, era obrero laico de la iglesia presbiteriana del lugar y ferviente socialista. Asimismo, Blanco fue, en 1908, uno de los fundadores de la iglesia evangélica de Muna junto con su hermano Asunción. ${ }^{7}$

Debido a su gran popularidad entre los campesinos por sus ideas socialistas, Blanco fue candidato del Partido Socialista y electo presidente municipal de Muna en el período de 1916-1917. Años atrás, cuando fijó su residencia en este lugar, en 1910, había organizado una "Sociedad de Temperancia” para evitar el consumo de alcohol entre la población. Posteriormente desempeñó un cargo en el ramo de alcoholes de la Secretaría General del Gobierno del Estado de Yucatán para luego ocupar, en noviembre de 1917, la jefatura del Depósito de Alcoholes en el gobierno estatal durante la gestión de Carlos Castro Morales. ${ }^{8}$

Por otra parte, la familia Carrillo se había establecido en Muna décadas atrás procedente de Santa Elena, pueblo vecino, cercano a Uxmal, y había adquirido un poder político y económico a nivel local desde fines del siglo xIx; muestra de esto fue que compró varias casas en el centro del pueblo donde residían, y que algunos de sus miembros, como Bartolomé Asísclo y Sóstenes Carrillo, fueron comerciantes y propietarios de pequeños parajes agrícolas, donde criaban ganado vacuno y sembraban a pequeña escala henequén y maíz, y habían ocupado cargos en el ayuntamiento local. Buena parte de su éxito económico se debió a la venta y distribución de alcohol de caña expendido en sus propias tiendas o en algún cuarto anexo a ellas. La venta de aguardiente era mayor cuando el pueblo se encontraba de fiesta, por ejemplo durante el carnaval y las fiestas del santo patrono. Los Carrillo y otras familias como Cabrera y Fajardo, por citar algunas, controlaban el comercio de maíz y alcohol, y ponían y quitaban autoridades a su conveniencia. Fue por eso que, a partir de que los hermanos Blanco empezaron a tener presencia social y política en la población, cuando la Iglesia presbiteriana se estableció en Muna, los Carrillo vieron a éstos como fuertes adversarios y competidores. Debido a que esta iglesia había atraído numerosos adeptos en el lugar y a que Liborio Blanco tuvo cierto liderazgo entre un segmento de la población, Manuel Carrillo, hijo de Sóstenes del mismo apellido, vio a este personaje con cierto recelo al principio y con abierto desafío después, de tal suerte que en no pocas ocasiones lo obligó, pistola en mano, a salirse de la población. ${ }^{9}$

Puede decirse que estos brotes de violencia fueron generalizados en Yucatán en los años siguientes al inicio de la Revolución mexicana y acrecentados durante el período socialista de Carrillo Puerto. En este sentido, podemos inferir que los

${ }^{7}$ La Revista de Yucatán, Mérida, Yucatán, 3 de julio de 1919

${ }^{8}$ Arturo Chin May, "Breve reseña histórica de la iglesia presbiteriana", Por Esto! Sección Municipios, Mérida, miércoles 31 de mayo de 2000, p. 21; La Razón, Mérida, Yucatán, 31 de enero de 1919.

${ }^{9}$ Entrevistas realizadas a los Señores Francisco, Víctor y Asisclo Carrillo Herrera, Luis Arana, Augusto Sosa y Lorenzo Pacab, Muna, Yucatán, febrero y marzo de 2002. 
enfrentamientos entre "los del centro" o ts'uules y los jornaleros, campesinos y empleados mayas de Muna tuvieron sus orígenes, dados los actores involucrados, en las revueltas encabezadas por Loreto Baak y Manuel Mendoza Rosado en 1911 (Medina Un, 2010) y 1912 durante los llamados "Sucesos de Uxmal"; principalmente en este último año, cuando Loreto Baak, de Santa Elena, y Bonifacio Alvarado, de Muna, junto con otros, asaltaron la presidencia municipal de Muna, amagaron a varios de los concejales allí reunidos, entre ellos a los hermanos Arturo y Desiderio Villalobos (parientes de los Carrillo), quemaron los archivos de ese cuerpo municipal y saquearon el establecimiento del comerciante otomano Abraham T. Said. Julio Couoh, vecino de la finca Yaxhá, quien formaba parte de los sublevados, fue quien finalmente dio muerte a los hermanos Villalobos ${ }^{10} \mathrm{y}$ a quien veremos después como uno de los cabecillas de los sucesos de Muna de 1919.

A partir de este último hecho hubo una serie de venganzas "menores" de parte de "los del centro" contra los involucrados en la revuelta, principalmente el incendio de sus hogares. Situación que fue constante durante los años que duró el socialismo en Yucatán.

Volviendo a los "sucesos de 1919", podemos afirmar que existe evidencia de que en los meses previos a ellos, Liborio Blanco, junto con Pedro Adarcilio Romero, pastor del templo presbiteriano de Muna, y Plácido Lope, destacado presbiteriano y jefe de la bolsa de trabajo de la finca Yaxhá, hacían constantemente propaganda socialista y evangélica en las fincas del municipio, en abierto desafío a los liberales católicos. ${ }^{11}$

Muestra de esto último se dio en el mes de mayo de 1919; según dos testigos, un profesor y el encargado de la finca refirieron que Lope había enviado un telegrama al comisario de la finca Yaxhá, señor Anselmo Nabté, para que reuniera a toda la gente del lugar en la plazuela de la finca con el propósito de tratar asuntos de trabajo. Reunidos en dicho lugar, Lope empezó a preguntar a los trabajadores acerca del trabajo en la hacienda y de las condiciones en que se encontraban. Después le dijo a la gente reunida que era preciso que no les regalaran su dinero a los comerciantes de Muna porque todos esos señores eran unos ladrones, citando entre ellos a los hermanos Sóstenes y Manuel Carrillo, así como a Delio Lara y otros. Luego el señor Lope invitó a los campesinos y jornaleros a que le enviaran el maíz cosechado a Mérida a cambio de remitirles mercancías a precios bajos. Al día siguiente se presentaron en Yaxhá los enviados de Lope a recoger el maíz, el cual fue despachado en la estación del ferrocarril de la finca a nombre de Lope y otros. ${ }^{12}$

${ }^{10}$ La Revista de Yucatán, Mérida, Yucatán, 25 de octubre de 1912; un estudio más amplio sobre el movimiento popular y los primeros brotes de violencia en el campo yucateco antes y durante la Revolución mexicana en Yucatán es el de Martha Medina Un, "El movimiento popular en Yucatán: 1897-1918”, tesis de licenciatura en Antropología Social, Mérida, Yucatán, Universidad Autónoma de Yucatán, Facultad de Ciencias Antropológicas, 1991. Gilbert Joseph y Allen Wells, 1996.

${ }^{11}$ La Revista de Yucatán, Mérida, Yucatán, 5 de julio de 1919.

${ }^{12}$ La Revista de Yucatán, Mérida, Yucatán, 5 de julio de 1919. 
A la semana siguiente, por la tarde, Pedro Adarcilio Romero se presentó en la finca Yaxhá, acompañado de aproximadamente 50 personas llevando la armónica o serafina, instrumento musical propio de las celebraciones religiosas. Más tarde se presentaron Plácido Lope en compañía de un hermano de Liborio Blanco, además de un norteamericano con su esposa e hijo. Estando todos reunidos en la plazuela de dicha finca iniciaron una función religiosa; como el profesor de la finca Yaxhá creyera que esta reunión entrañaba algún delito, dio cuenta al alcalde de Muna, Enrique Cáceres; pero éste se encontraba ausente del lugar. ${ }^{13}$

Por las desavenencias habidas entre los dos sectores de la población, unos a favor y otros en contra de la realización de la fiesta, y como parte de una estrategia para lograr su objetivo, Enrique Cáceres, alcalde municipal, junto con Serapio Cabrera, presentó ante el gobernador un memorial con 500 firmas pretendiendo avalar con esto la realización de la fiesta. El gobernador, para cerciorarse de la verdad, y a petición de los "ligados", nombró a Anatolio B. y Buenfil, destacado líder socialista, para que se hiciera cargo de organizar una elección entre los habitantes de Muna y ver "por qué lado estaba la mayoría".

Para dar cuenta a la Liga Central de Resistencia, Buenfil pidió al presidente de dicha agrupación, Felipe Valencia López, que nombrara a alguien para que lo acompañara. Llegando Buenfil a Muna, Enrique Cáceres le aconsejó que la urna de votación fuera colocada en la puerta del local de la "liga", pero aquél, previendo la intriga, mandó ponerla en la puerta de la presidencia municipal; el resultado, según el propio comisionado, es que salieron a votar solamente los indios, el "nervio del pueblo", ningún ts'uul, porque, según se dijo después, "para evitar choques" estos últimos no habían acudido a votar. ${ }^{14}$

Sin embargo, Cáceres y su comisión, no conformes con el resultado de dicha consulta, acudieron al gobernador con un nuevo memorial. Ante este hecho, Juan Solís dio aviso a Anatolio B. y Buenfil para que tomara cartas en el asunto, pero éste le recomendó hablar con Pedro Romero, diputado federal al que pertenecía el municipio de Muna. ${ }^{15}$ Desconocemos la resolución que este diputado dio a los inconformes, lo que fue un hecho es que los socialistas, viendo que sus peticiones no eran escuchadas de manera satisfactoria y para impedir los festejos, ingresaron a la iglesia católica en la madrugada del 6 de mayo de 1919, según algunos con el pretexto de disparar unas "salvas", con motivo de los festejos del 5 de mayo, día de la Batalla de Puebla. Esa misma noche extrajeron de la iglesia la imagen del Cristo de Uxmal; al día siguiente, al ingresar al templo, los católicos se percataron de la ausencia de la imagen. ${ }^{16}$

${ }^{13}$ La Revista de Yucatán, Mérida, Yucatán, 3 de julio de 1919.

${ }^{14}$ La Revista de Yucatán, Mérida, Yucatán, 3 de julio de 1919.

${ }^{15}$ La Revista de Yucatán, Mérida, Yucatán, 3 de julio de 1919.

16 AGeY Fondo Poder Judicial del Estado de Yucatán, Sección Departamento Judicial de Ticul (06), Serie: Juzgado de $1^{\mathrm{a}}$ Instancia, Ticul (46). "Diligencia/Causa seguida por robo". Alcaldía Municipal de Muna, 1919. 
El hecho fue turnado a las autoridades correspondientes, primero al juez $1^{\circ}$ de paz Adolfo Sosa y después al Ministerio Público de Ticul. En las averiguaciones salió a relucir que en las inmediaciones del templo católico, en la calle que separa ambos templos y en el propio templo presbiteriano de Muna, situado frente al católico, fueron encontrados algunos fragmentos de las alhajas que portaba la imagen. ${ }^{17}$ Los católicos de Muna culparon a los presbiterianos/socialistas de la desaparición de la imagen de Uxmal.

La mayor parte de los declarantes manifestaron no tener sospechas de los culpables del robo, no obstante, Serapio Cabrera, comerciante, hacendado y uno de los principales interesados en la realización de la mencionada fiesta, se presentó ante el juzgado constituido y con el "fin de expeditar el esclarecimiento del delito que se persigue" dijo tener conocimiento, por denuncia que se le hizo, de que los principales autores del robo de la imagen de Uxmal fueron: José Encarnación Domínguez, Julián Ortíz, Simón Santos, Alberto Keb y Froilán y Eulalio Chalé, quienes - según Cabrera- sacaron al Cristo de la iglesia principal del lugar bajo la protección de los socialistas, "con el pretexto de hacer descargas" con motivo de las fiestas del " 5 de mayo" 18 como se ha visto.

Aún sin contar con pruebas suficientes y sin haber podido inculpar a ningún sospechoso, el 11 de mayo de ese mismo año, o sea, cinco días después del robo, unos niños que andaban "tirando pájaros" encontraron accidentalmente al Cristo robado en el interior del pozo del paraje yermo San Erasmo, anexo de la hacienda Sahcabá situado media legua al poniente de Muna, por el camino que conduce a Opichén. A ese lugar acudieron el alcalde, Enrique Cáceres, el comandante de la policía constitucionalista, Pedro Sierra, el jefe de la policía municipal, Aquileo de la O, Rudecindo Valencia, responsable del cuidado del santo, y los señores Olegario Vázquez, Fabián Valencia, Dolores Maldonado, Silvestre Cetz y Juan Salas para cerciorarse y atestiguar el hecho. Una vez seguros de que se trataba de la misma imagen desaparecida, ordenaron la extracción de los fragmentos.

Las piezas encontradas en el interior del pozo eran efectivamente de la imagen robada, y fueron las siguientes: el cuerpo sin cabeza ni extremidades, la cabeza, dos partes sueltas del cuerpo, los dos brazos sueltos, las dos piernas sueltas, una de ellas con su pie, un pie suelto, la tabla de InRI suelta, dos accesorios de madera que sirven para colocar el sudario, tres pedazos de la cruz sueltos, dos de ellos con sus clavos, y seis astillas del propio santo. No apareció en el pozo

${ }^{17}$ El Cristo de Uxmal tenía como parte de su vestuario varias alhajas, entre ellas: una corona de púas con sus tres "potencias", toda de oro, veintiocho azucenas de oro; treinta "rescates" de oro y de plata en los brazos y en los pies; los clavos de oro necesarios con sus estrellas. Además de las mencionadas alhajas, el día del robo, la imagen portaba un sudario nuevo de raso bordado con seda, pues era costumbre de los fieles obsequiar una alhaja o una prenda nueva cada año.

${ }^{18}$ AgEY Fondo Poder Judicial del Estado de Yucatán, Sección Departamento Judicial de Ticul (06), Serie: Juzgado de $1^{a}$ Instancia, Ticul (46). "Diligencia/Causa seguida por robo”. Alcaldía Municipal de Muna, 1919. 
alhaja alguna a excepción de dos clavos con sus cabezas y adornos, al parecer de oro. Luego, el santo, o lo que quedó de él, custodiado por el destacamento federal de Muna, fue trasladado al local que ocupaba la alcaldía. ${ }^{19}$

En un primer momento, culparon a la señora Escolástica Romero, madre del pastor de la iglesia presbiteriana, Pedro Adarcilio Romero, ambos habitantes del edificio, lugar donde según se dijo habían encontrado fragmentos de las alhajas del Cristo. En su defensa, la señora Romero argumentó que fueron los propios católicos los que habían introducido las alhajas en el templo, debido a que, al inicio de las averiguaciones, una muchedumbre de católicos ingresó a él de manera atropellada. En su declaración dijo conocer la imagen aludida porque desde niña era llevada por sus padres hasta la hacienda Uxmal, pero que, dado que había sido convertida cinco años atrás a la religión presbiteriana, no conocía las nuevas alhajas del santo, que las que ella conoció eran de plata.

Sin embargo, el juzgado constituido no pudo imputar a esta señora el delito del que se le acusaba y fue suspendido debido a la falta de evidencias contundentes. Las autoridades no encontraron a los culpables del delito de robo. ${ }^{20}$

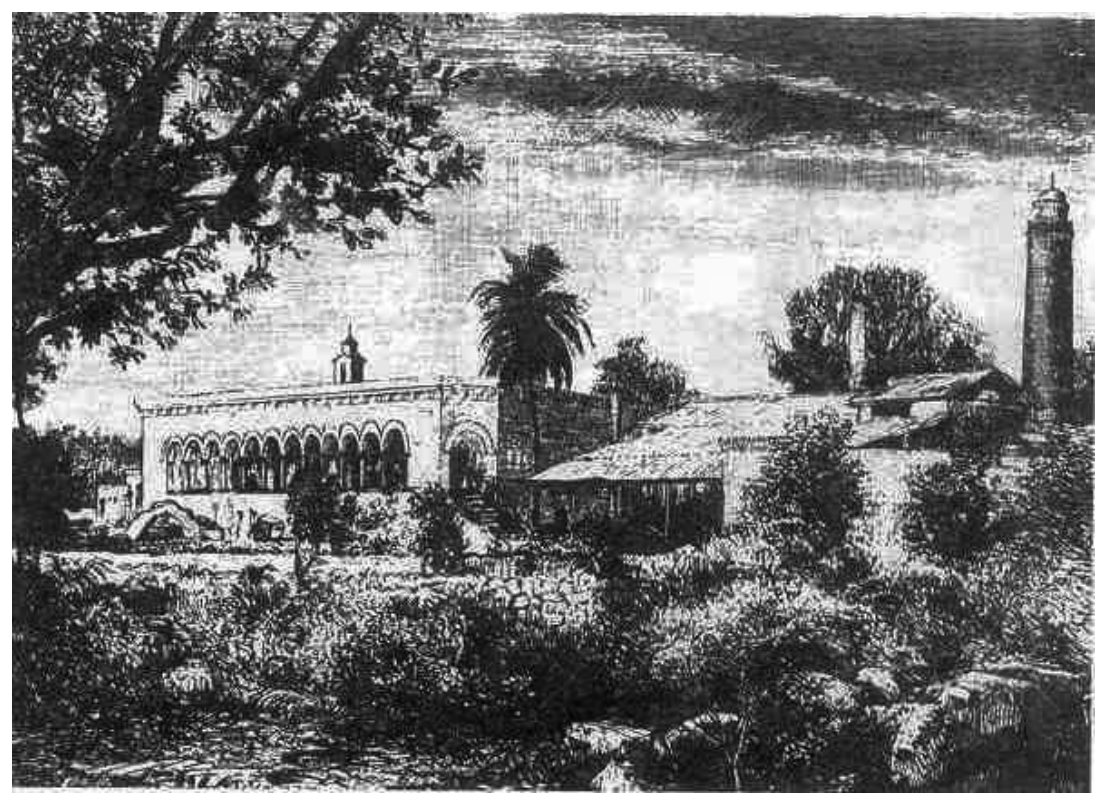

FIGURA 2. Casa principal de la hacienda Uxmal, ca. 1886. Charnay [1883] (1992).

${ }^{19}$ AGEY Fondo Poder Judicial del Estado de Yucatán, Sección Departamento Judicial de Ticul (06), Serie: Juzgado de $1^{\mathrm{a}}$ Instancia, Ticul (46). Caja 105, vol. 105, exp. 13866.

20 AGEY Fondo Poder Judicial del Estado de Yucatán, Sección Departamento Judicial de Ticul (06), Serie: Juzgado de $1^{\mathrm{a}}$ Instancia, Ticul (46). Caja 105, vol. 105, exp. 13866. "Diligencia/Causa seguida por robo". Alcaldía Municipal de Muna, 1919. 


\section{El preludio de la tragedia}

En un principio, las diligencias legales practicadas en torno al esclarecimiento del robo fueron llevadas a cabo por el juez $1^{\circ}$ de paz de Muna, Adolfo Sosa, turnándoselas posteriormente al juez de $1^{\mathrm{a}}$ instancia de Ticul, el licenciado Miguel Badillo Superano, llegando después al juzgado de distrito del estado de Yucatán por haberse considerado el caso un delito federal. Después se supo que el robo pertenecía al fuero común y que Augusto L. Peón, hacendado meridano y propietario de la hacienda Uxmal, era único y legítimo dueño del Cristo.

Después de los trámites legales, la imagen, o lo que quedó de ella, fue entregada por la autoridades correspondientes, el 27 de mayo de $1919,{ }^{21}$ a uno de los promotores de la fiesta, el señor Serapio Cabrera, apoderado legal del señor Peón. Aún sin haber sido restaurados, pues ya se tenía la aprobación de parte del gobierno del estado para la realización de la fiesta, ${ }^{22}$ los fragmentos de la imagen fueron llevados al barrio de San Bernardo, y el santo fue festejado con corridas de toros, peleas de gallos, vaquerías y bailes de etiqueta durante los días que corrieron del 28 de mayo al 1 de junio. En la figura 3 se muestra el programa de actividades publicado el 25 de mayo de 1919 en La Revista de Yucatán. ${ }^{23}$

No hemos podido determinar de manera fehaciente porque la fiesta patronal de Muna, la más importante del calendario de festividades católicas, era celebrada en el barrio de San Bernardo, situado al sur de la población, junto al pu'uk (cerro). Sin embargo, podemos proporcionar algunos datos históricos que expliquen de manera plausible esta situación. Varias de las familias acomodadas de Muna tenían lazos muy fuertes con la vecina Santa Elena (la antigua Nohcacab),

${ }^{21}$ En este acto, el C. juez dispuso que se entregaran al compareciente señor Cabrera el Cristo y anexos que le pertenecen, los cuales fueron los siguientes: dos clavos con sus cabezas y dos planchuelas que tiene cada uno de los clavos, al parecer de oro; cuatro rescates o amuletos, al parecer de plata con sus cintillas; un pedazo de corona de pulgada y media de largo aproximadamente, al parecer de oro; un tridente de oro denominado "tres potencias"; ocho azucenas, al parecer de oro en buen estado; una azucena, al parecer de oro con una hojita desprendida; una azucena de piedras ordinaria en forma de fistol; un bastoncillo o alfiler de oro; una corona de plata; dos laminitas y una cabeza de clavo, al parecer de oro; un pedazo de cerradura, al parecer de hierro colado; dieciséis pedazos de madera del Cristo de Uxmal, que se especifican de la manera siguiente: rostro, caja del cuerpo, dos brazos, dos caderas del sudario, dos piernas, una de ellas con su pie, un pie, la tabla de INRI, una pieza del abdomen, una mano, cinco fragmentos del mismo Cristo y cuatro pedazos de la cruz. Enseguida, el C. Serapio Cabrera se dio por recibido de todos y cada uno de los objetos relacionados a su entera satisfacción, los cuales, desde este momento, se encuentra en su poder, y dijo que por su parte no tiene que reclamar nada más así como tampoco nada que objetar, con lo que se dio por terminada la diligencia. Agey Fondo Poder Judicial del Estado de Yucatán, Sección Departamento Judicial de Ticul (06), Serie: Juzgado de $1^{\text {a }}$ Instancia, Ticul (46). "Diligencia/Causa seguida por robo". Alcaldía Municipal de Muna, 1919.

${ }^{22}$ La Revista de Yucatán, Mérida, Yucatán, 21 de mayo de 1919.

${ }^{23}$ La Revista de Yucatán, Mérida, Yucatán, 25 de mayo de 1919. El 25 de mayo de 1919 se publicó la nota en el periódico, la fecha que aparece en el anuncio es la del día en que fue remitido el escrito desde Muna y firmado por el corresponsal de la Revista en este mismo lugar. Este anuncio fue copiado por mi de manera textual. 


\section{"Rumbosa fiesta en el barrio de San Bernardo de la Villa de Muna"}

Después de varios años de no verificarse esta fiesta, hoy, con inusitado entusiasmo se ha acordado llevarla a cabo bajo el siguiente programa:

Programa

En la noche del28 actual, suntuosa vaqueria en la que tomarán parte la simpáticas señoritas de la localidad y poblaciones comarcanas, luciendoel típico traje de mestizas.

Al medio dia del 29, repetición del baile de vaqueras en el que no faltará el clásico puuk' $k^{\prime}$ eyem preparado por divinas manos, acompañado del exquisito ts'otobi chaay. Desde la noche de este día hasta $\mathrm{el} 1^{\circ}$ de junio entrante, suntuosos bailes de etiqueta en un salón preparado ad hoc con sugestivos adornos y hermosamente iluminado.

En el transcurso de estos mismos días, y sin un momento de paréntesis; habrá carreras de caballos y argentinas, juego de pelota, tiro al blanco, funciones de cine, tómbolas y la mar de diversiones para chicos y grandes. También se están instalando fondas y puestos de refresquerías en donde se recibirá todo tipo de moneda, inclusive "cartones".

Una competente orquesta bajo la dirección del entendido filarmónico $\mathrm{D}$. Tomás Martín, amenizará todos los números del programa de la fiesta, estrenándose hermosas piezas de música de renombrados autores. Se hace especial invitación a yucatecos y campechanos, a fin de que nos honren con su presencia brindándoles cordial acogida y esperándolos con los brazos abiertos.

Muna, mayo 20 de 1919

Por la comisión

Manuel Carrillo Rodríguez

Figura 3. Nota periodística anunciando la fiesta en honor al Cristo de Uxmal La Revista de Yucatán, Mérida 25 de mayo de 1919.

de manera que familias con apellidos como Carrillo, Lara, Arana, Lizárraga, por citar sólo a los más importantes, habían arribado a Muna procedentes de ese pueblo en los años más álgidos de la Guerra de Castas en esta región, cuando la entonces Nohcacab fue saqueada y quemada por las tropas del gobierno de Yucatán (Ancona, 1978: 145-146). Dichas familias salieron huyendo de la persecución y la violencia, asentándose, entre otros lugares, en Muna. Podemos proponer como hipótesis que esta misma gente había tenido fervor hacia el Señor de Uxmal desde su residencia en Nohcacab y posteriormente en Muna, continuado como se ha visto.

Asimismo, un buen número de campesinos, jornaleros y empleados mayas y no mayas de la hacienda Uxmal y de Nohcacab pudieron haber abandonado su pueblo natal y haberse establecido en las inmediaciones del barrio de San Bernardo. Seguramente eran devotos del Señor de Uxmal y con el paso del tiempo encontraron otros adeptos entre los vecinos del mismo barrio, quienes 
promovieron el culto a dicha imagen. Todavía hasta la segunda mitad del siglo xx podíamos encontrar familias mayas con el patronímico Baak, Nah y otros que referían haber tenido abuelos o padres originarios de Santa Elena o residentes en las hacienda Sakakal y Uxmal. ${ }^{24}$

Fue entonces que, a partir del 2 de junio de 1919, después de la fiesta, Muna vivió una aparente calma; las autoridades encargadas del caso del robo continuaron sus averiguaciones y, el 21 de junio de ese mismo año, el juez de distrito del estado remitió al juez de $1^{\mathrm{a}}$ instancia de Ticul el expediente para que éste le diera continuidad al asunto. ${ }^{25}$

Pero las reacciones no se hicieron esperar, según los socialistas, los organizadores de la fiesta se habían burlado del pueblo por festejar al Cristo a pesar de la oposición de un sector de la población. Lo que a continuación se verá parece sugerir una venganza premeditada y planeada por parte de los socialistas en contra de los organizadores de la fiesta y otras personas acomodadas, principalmente.

\section{Los "sucesos" del 27 de junio de 1919}

En la tarde del 27 de junio de 1919, Enrique Cáceres, alcalde de Muna, tuvo conocimiento de que "algo grave" iba a suceder ese día, pues circuló el rumor "de asesinar a determinadas personas y saquear los establecimientos comerciales e incendiar los edificios de las familias acomodadas". ${ }^{26}$ Esto no llamó mucho la atención porque en otras ocasiones se había dicho lo mismo sin que se llevara a cabo, como por ejemplo cuando Liborio Blanco trató de alentar a los socialistas para "provocar un escándalo" en contra del alcalde Enrique Cáceres en marzo de ese mismo año. ${ }^{27}$

A pesar de ello y por ese motivo, Cáceres, junto con Manuel Carrillo y el comandante del destacamento federal Aquileo de la O, alertaron a los comerciantes para que cerraran sus negocios y se prepararan para la defensa. Estas mismas personas fueron a ver a "un grupo de amigos, ajenos a la política" que vivían en el barrio de San Bernardo para pedirles ayuda "para cualquier evento". Como a las cuatro de la tarde, el alcalde, Carrillo y el comandante fueron a la estación del ferrocarril para enviar un telegrama de auxilio al destacamento militar de Ticul, así como al propio alcalde de ese lugar y al jefe de operaciones militares del estado, Luis H. Hernández. La guarnición de Muna, compuesta por una decena de soldados, sería insuficiente para darles garantías a los habitantes. Cáceres y sus socios habían planeado reunirse a las nueve de la noche en el palacio municipal

\footnotetext{
${ }^{24}$ Entrevista a la profesora Violeta Arana Villalobos, Muna, Yucatán, 22 de diciembre 2010.

${ }^{25}$ AgeY Fondo Poder Judicial del Estado de Yucatán, Sección Departamento Judicial de Ticul (06), Serie: Juzgado de $1^{\mathrm{a}}$ Instancia, Ticul (46). "Diligencia/Causa seguida por robo". Alcaldía Municipal de Muna, 1919.

${ }^{26}$ La Revista de Yucatán, Mérida, Yucatán, 30 de junio de 1919.

${ }^{27}$ La Revista de Yucatán, Mérida, Yucatán, 22 de marzo de 1919.
} 
para repeler a sus atacantes, previendo que el ataque por parte de los socialistas sería efectuado en la madrugada. ${ }^{28}$

A las 7:30 p.m., viendo que el auxilio no llegaba, se dirigieron a reiterar el telegrama. Camino a la estación del ferrocarril, próxima a la casa de Manuel Castillo, fueron atacados por los socialistas que habían disparado contra la tienda de este último. ${ }^{29}$

No obstante, las previsiones no prosperaron, ya que los atacantes se adelantaron a los pronósticos. Aproximadamente a las 19:30 horas del 27 de junio de 1919, Muna fue asaltada por un numeroso grupo de socialistas armados con escopetas Wínchester, machetes y explosivos; fueron incendiadas alrededor de cuarenta casas, asesinadas — se dijo- cerca de 20 personas y heridos otros tantos. ${ }^{30}$ Los principales comercios fueron saqueados y quemados, y algunos de ellos destruidos con dinamita. Fueron víctimas de esto los organizadores de la fiesta al Cristo de Uxmal y otros comerciantes, como los señores Sóstenes, Manuel, Francisco y Tárcilo Carrillo, Serapio Cabrera, Delio Lara, Enrique Cáceres y Manuel Castillo, quienes poco pudieron hacer para defender sus propiedades. A Serapio Cabrera, además de dinamitar su tienda, le destruyeron la casa principal y la maquinaria de su pequeña finca henequenera "San Gregorio". Uno por uno, los comercios señalados fueron cayendo en manos de los socialistas; sin embargo, los propietarios lograron escapar. Los más señalados para asesinar ese día fueron Manuel y Sóstenes Carrillo, así como Serapio Cabrera. ${ }^{31}$ Práxedes Zavala, el escultor que había sido contratado para restaurar al Cristo de Uxmal, fue ultimado ese mismo día cuando se encontraba trabajando la imagen en la casatienda de Sóstenes Carrillo. Fue macheteado por los alzados, luego rociado con petróleo junto con el Cristo y posteriormente se les prendió fuego. ${ }^{32}$

Algunas fuentes mencionaron que, el día de los sucesos, los socialistas, al momento de atacar a la población, "gritaban desaforadamente y como en la Guerra de Castas de 1847, se pintaron la cara y el cuerpo, se desnudaron apenas cubriéndose con un taparrabo y disfrazándose otros el rostro para no ser identificados"33 e iban vitoreando a Felipe Carrillo Puerto, Pedro Adarcilio Rome-

${ }^{28}$ La Revista de Yucatán, Mérida, Yucatán, 5 de julio de 1919.

${ }^{29}$ La Revista de Yucatán, Mérida, Yucatán, 5 de julio de 1919.

30 Según La Revista de Yucatán, de fecha 30 de junio de 1919, los muertos fueron los siguientes: Raymundo Rodríguez, Práxedes Zavala, Eugenio Chalé, Marcelina Huacal, Marcelina Arana, Fidelio Mex, Antonio Lara, Prudencio Gamboa, Alfredo Torres, Antonio Suárez, Fabián Lara, Juan Salas, Santiago Romero, Exiquio Carrillo, Augusto Sosa, Santiago Paredes y Andrés Avelino López. Timoteo Caamal y Francisco Baas fueron asesinados en la refriega que hubo al tiempo de ser aprehendidos por los policías Mateo Negrete, Francisco Ortíz y Rómulo Pech.

${ }^{31}$ La Revista de Yucatán, 1213, Mérida, Yucatán, domingo 29 de junio de 1919; El Correo, Mérida, martes 8 de julio de 1919

${ }^{32}$ La Revista de Yucatán, Mérida, Yucatán, domingo 29 de junio de 1919

${ }^{33}$ El Correo, Mérida, Yucatán, 11 de agosto de 1919. En esta edición fue publicada la declaración que el general Luis H. Hernández, jefe de operaciones militares en los Estados de Yucatán y Campeche, dio al general Juan Barragán, jefe del Estado Mayor Presidencial, misma que remitió a los representantes de la prensa nacional y al presidente Carranza. 
ro, Liborio Blanco y Plácido Lope; el primero, líder principal del Partido Socialista del Sureste, y los tres últimos, personajes destacados de la iglesia presbiteriana de Muna y Ticul respectivamente, quienes, según algunos, constantemente realizaban propaganda socialista y evangélica en las fincas y barrios de Muna. ${ }^{34}$

En los siguientes días, varias voces se alzaron; el Partido Liberal culpó a Felipe Carrillo Puerto de lo acontecido por haber sido el principal agitador de los campesinos mayas en el interior de Yucatán. También inculparon a los presbiterianos de Muna y a sus principales líderes, Liborio Blanco y Plácido Lope.

El 29 de junio de 1919, la prensa conservadora, en La Revista de Yucatán, dio a conocer los hechos de manera parcial nutriéndose de la información proporcionada por su corresponsal en Muna, el señor Manuel Carrillo, destacando que lo ocurrido había sido motivado por diferencias religiosas entre católicos y presbiterianos, por la oposición que estos últimos tuvieron en la realización de la mencionada fiesta en honor al Cristo de Uxmal, santo patrono de Muna, ${ }^{35}$ y que habían tomado parte de la revuelta evangélicos de las haciendas Yaxhá y Choyob y del pueblo de Opichén.

El 3 de julio de ese mismo año, sin embargo, Asunción Blanco Rosado, ministro de la Iglesia Evangélica de Yucatán y hermano de Liborio del mismo apellido, dio su opinión respecto de los hechos en La Revista de Yucatán, según él, "para que sepan que los protestantes de Muna no son los responsables de los sucesos de allí y mucho menos han fomentado la división..." a la que arguiía dicho periódico. Asunción Blanco dio una interpretación de los hechos mencionando que la división entre los munenses se dio por causa de unas cuantas personas, dice así en un remitido enviado a Carlos R. Menéndez, entonces director de $L a$ Revista de Yucatán:

[...] si es que existe alguna división en Muna, como queda asentado [en La Revista de Yucatán], nunca pueden ser culpables los protestantes de aquel lugar, si se toma en consideración que hace once años que se estableció allí, la Iglesia Evangélica Protestante y durante el tiempo transcurrido desde 1908 hasta el principio del año actual, siempre se han llevado bien los católicos romanistas y evangélicos protestantes, con excepción, como es natural, de unos cuantos vecinos de Muna, quienes acostumbrados a explotar como en épocas pretéritas la credulidad religiosa y el trabajo personal de la mayoría, han venido laborando, tres años atrás, en contra de los protestantes, pero esa actitud no es de extrañarse; toda vez que los hombres parásitos se disgustan cuando ven el bien perdido. Con tal motivo, atribuyeron a

${ }^{34}$ La Revista de Yucatán, Mérida, Yucatán, 30 de junio de 1919

${ }^{35}$ La Revista de Yucatán, Mérida, Yucatán, 29 de junio de 1919. En la edición de este día publicó en su primera plana el título "La San Bartolomé de anteanoche en la Villa de Muna. Los fanatismos religioso y político ensangrentaron, en salvaje festín, las tranquilas residencias de pacíficos vecinos", encabezado que hizo referencia al conflicto religioso ocurrido en Francia en el siglo xvi, Massacre de la Saint-Barthélemy, el cual consistió en el asesinato en masa de hugotones, cristianos protestantes franceses de doctrina calvinista, durante las guerras de religión de Francia en el siglo xvı, comenzando el 24 de agosto de 1872 en París y extendiéndose en los meses siguientes por todo el país, en línea: http://es.wikipedia.org/wiki/Matanza_de_San_Bartolom\%C3\%A9. 
los protestantes de Muna, el robo del Cristo de Uxmal... (La Revista de Yucatán, 3 de julio de 1919)

Según la misma fuente periodística, fueron entre 600 y 700 los hombres que tomaron parte en el asalto a Muna ${ }^{36}$ señalándose como los principales cabecillas a Juan Solís, Manuel y Francisco Baas, Silverio Cetina, Julio Couoh e Idelfonso Koh. Asunción Blanco respondió que la Iglesia Presbiteriana en Muna no contaba ni con 100 elementos entre sus filas y que estos individuos, todos socialistas, no figuraban en las listas de miembros de dicha iglesia. ${ }^{37}$ Días después apresaron a Juan Ferráez en una sascabera ${ }^{38}$ y a Alberto Keb alias Farfán, autor del asalto a la hacienda "San Gregorio", propiedad de Serapio Cabrera. ${ }^{39}$

Pero no sólo la Iglesia Presbiteriana protestó por los hechos, también lo hizo el Partido Socialista, de tal manera que el 3 de julio de 1919, La Revista de Yucatán publicó un manifiesto de Felipe Carrillo y del diputado Anatolio B. Buenfil, misma que fue leída en la Cámara de Diputados el 12 de julio del mismo año por el diputado Castillo Torre. En él manifestaban que los verdaderos culpables habían sido Manuel y Sóstenes Carrillo y Enrique Cáceres, hacendados, a quienes también acusaban de esclavistas y pixoyeros (expendedores de licor barato) y de que eran los organizadores y principales beneficiados de la fiesta. ${ }^{40}$ En este mismo documento, el diputado Buenfil señaló que Serapio Cabrera se había ufanado en los corredores de la Comisión Reguladora del Mercado de Henequén, en Mérida, ante otros hacendados, de que él solo "se había mandado" a 12 trabajadores socialistas. ${ }^{41}$

El documento fue leído a petición de Carrillo Puerto, ya que, según él, a raíz de los "sucesos" de Muna, se habían cometido atropellos, asesinatos y detenciones injustificadas en contra de los socialistas. En un telegrama enviado a Castillo Torre, se refiere así a los "sucesos":

Mérida, Yucatán, el 5 de julio de 1919.

Señor licenciado José Castillo Torre. - Cámara de Diputados.

Con motivo sucesos Muna, general Luis M. Hernández cerca cien trabajadores fueron aprehendidos en sus propias casas y conducidos como prisioneros de guerra, desde domingo en la mañana hasta hoy, sin ponerlos disposición ninguna autoridad competente; mismo señor general Hernández espera instrucciones señor presidente República para filiar trabajadores en distintos batallones están interior República. Como este acto es inhumanitario y es acto con que acostumbró tiranía imponerse este Estado, suplícole le haga llegar nuestra voz de protesta a toda la Nación mexicana, en unión de todos nuestros amigos que están en esa, para

${ }^{36}$ El Correo, Mérida, Yucatán, 7 de julio de 1919.

${ }^{37}$ La Revista de Yucatán, Mérida, Yucatán, 3 de julio de 1919.

${ }^{38}$ Cueva donde se extrae material pétreo para la construcción de casas

${ }^{39}$ El Correo, Mérida, Yucatán, 7 de julio de 1919.

${ }^{40}$ Diario de los Debates de la Cámara de Diputados, 12 de julio de 1919, no. 64

${ }^{41}$ Diario de los Debates de la Cámara de Diputados, 12 de julio de 1919, no. 64 
ver no se lleve a cabo tan gran atentado, pues dichos trabajadores son inocentes cuanto ha sucedido en Muna. Impunidad es tan grande, que han sido fusilados sin formación causa, seis trabajadores sacados de sus casas a viva fuerza por mismos soldados y al poco tiempo han sido quemadas sus casas. Es necesario tú hagas saber a todos compañeros nuestros en esa honorable Cámara para que sepa cómo se trata al Estado de Yucatán, que es fuente de la riqueza nacional. Estos atentados son cometidos en las personas de todos los socialistas, pues no hay un pueblo en el Estado donde no se atropellen trabajadores ligas de resistencia por fuerzas federales. Afectuosamente, Felipe Carrillo. ${ }^{42}$

Con motivo de los sucesos de Muna, fueron aprehendidos poco más de 50 personas, en su mayoría jornaleros y campesinos mayas, mismos que fueron embarcados, a pesar del amparo solicitado, ${ }^{43}$ en el vapor "Tamaulipas" desde el puerto Progreso hasta Veracruz y de ahí trasladados a la Ciudad de México para ser juzgados por el delito de rebelión. ${ }^{44}$ Sin embargo, la mayor parte de estos fueron liberados días después, y embarcados de regreso a Yucatán, a donde llegaron el 23 de julio en el vapor "Coahuila", esto gracias a las gestiones hechas por el diputado local Manuel Berzunza, quien a su vez culpó al general Luis H. Hernández, Jefe de las Operaciones Militares del Estado de Yucatán, de lo sucedido en Muna. A principios de agosto de ese año fueron puestos en libertad 42 de los 57 presos, y los 15 restantes recibieron auto de formal prisión por disposición de las autoridades locales encabezadas por el licenciado Fernando Peniche López. ${ }^{45}$

Otra fuente mencionó que fueron 13 los formalmente presos, quienes serían juzgados por los delitos de asonada o motín y de sus conexos, homicidio, lesiones y destrucción en propiedad ajena por incendio. ${ }^{46}$ El periódico El Correo, por su parte, informó el 5 de agosto del mismo año que fueron 9 los formalmente presos: Donato Nabté, Pedro González, Felipe Castro, Juan Paredes, Nicolás Far-

${ }^{42}$ Diario de los Debates de la Cámara de Diputados, 12 de julio de 1919, no. 64

${ }^{43}$ La Revista de Yucatán, Mérida, Yucatán, 6 y 10 de julio de 1919. El amparo, con carácter de urgente, fue solicitado al Juez de Distrito del Estado por la señora Demetria Solís a nombre de los ciudadanos Plutarco Martínez, Rafael González y otros, presos en el Cuartel de Dragones de Mérida. En dicho documento se acusaba al presidente de la República, al jefe de Operaciones Militares en el Estado, general Luis H. Hernández, y al jefe del Batallón del mencionado Cuartel por violación a los artículos 1, 13, 14, 16, 19 y 22 de la Constitución General de la República.

${ }^{44}$ Los presos que fueron embarcados en el vapor "Tamaulipas" en Progreso a principios de julio de 1919 iban custodiados por el mayor Isidro Rangel y 75 soldados del Batallón 65; los presos fueron: Damaso Delgado, Miguel Canché, José Isaías Kuk, Donato Nabté, Vicente Chan, Pedro Ferráez, Pedro González, Melquiades Duarte, Juan Chí, Cecilio Pech, Dionisio Pech, Feliciano Koh, José I. Paredes, Mariano Sanmiguel, Luciano Balam, Diego Martín, Daniel May, José Domínguez, Felipe Vera, Benigno Chan, Felipe Castro Herrera, Alberto Euán, José Paredes, Nicolás Farfán, Pablo Simá, Pablo Ferráez, Anselmo Tuyub, Emiliano Romero, José S. Yamá, Rafael González, Anastacio Yamá, Severo Huchim, Enrique Chan, Fabián Cárdenas, Ciriaco Chí, Pantaleón Mukul, Casimiro Chan, Felipe Baak, Pascual Huchim, Laureano Chuil, Bernardo León, Francisco Cauich, Silverio Dzib, Roberto Tuyú, Romualdo Vázquez, Emilio Farfán, Juan Pablo Chin, Carlos Mis y José Vadillo. La Revista de Yucatán, Mérida, Yucatán, 30 de junio de 1919. El Correo, Mérida, 18 de julio de 1919.

${ }^{45}$ El Correo, Mérida, Yucatán, ediciones de los días 19, 24 y 25 de julio, 11 y 13 de agosto de 1919.

${ }^{46}$ La Revista de Yucatán, Mérida, Yucatán, 11 de julio de 1919. 
fán, Pablo Ferráez, Anselmo Tuyub, Rafael González y Emilio Farfán. Sin embargo, no coinciden con los nombres publicados en esos días por La Revista de Yucatán: Manuel Valencia, Asunción Polanco, Espiridión Tun, Eulalio Domínguez, Ceferino Matú, José Ferráez, Alberto Farfán Keb, Florentino Pacheco, José Isaac Farfán, Tomás May, Lorenzo Chan, Victoriano Canché y José Eugenio Carrillo. ${ }^{47}$ Lo que fue un hecho es que los principales cabecillas del movimiento, mencionados líneas arriba, lograron escapar, y se les puede ubicar en los siguientes años involucrados en otros levantamientos menores.

Una respuesta contra las acusaciones que hicieron los dirigentes socialistas y presbiterianos hacia los comerciantes y organizadores de la fiesta en honor al Cristo de Uxmal se puede encontrar publicada en La Revista de Yucatán, firmada por Manuel y Sóstenes Carrillo, Serapio Cabrera, Enrique Cáceres y Delio Lara. Estos personajes tildaban a Carrillo Puerto de haber usado diatribas y discursos aviesos para acusarlos de los "sucesos" de 1919.

Sóstenes Carrillo y socios incluyeron en su protesta cuestiones étnicas que hasta entonces habían permanecido veladas. Afirmaron que Carrillo Puerto había excitado a las multitudes indígenas para que exterminaran a los "pocos blancos y mestizos que pueblan el estado de Yucatán”, cuando, según el escrito, estos eran necesarios para el progreso del pueblo, porque "ellos positivamente constituyen el único factor de progreso e iniciativa de esta misma entidad federativa" ${ }^{48}$ Hasta entonces la cuestión étnica no había aflorado como en la protesta de Carrillo Rodríguez y socios; si estaba presente, subyacía en el discurso tanto de un bando como del otro. Del lado de los socialistas usaban términos como explotadores, ts'uules o hacendados para nombrar a los no mayas, y por el lado de los liberales se referían a ellos como indígenas o indios, pero no habían hecho referencia a su supuesta "superioridad". Este escrito, cargado de la ideología dominante de la época, es quizá el punto culminante donde el grupo de los ts'uules demostró con el discurso que las disputas eran motivadas más bien por cuestiones de carácter político y étnico y en menor medida por lo religioso, como pretendieron que apareciera ante la opinión pública y las autoridades.

Así, podemos afirmar que el conflicto suscitado en Muna en 1919 fue de tipo étnico si atendemos a los actores involucrados: mayas, no mayas, y, entre los mayas mismos, los representados bajo los partidos políticos liberal y socialista. Pero más que nada consideramos que fue una lucha de clases alentada por la ideología socialista/marxista adoptada, en buena medida, por el Partido Socialista del Sureste, y que quedó plasmada cuando el Partido había adquirido una considerable fortaleza y madurez; esto puede verificarse en uno de los acuerdos tomados en el Segundo Congreso Obrero Socialista celebrado en la ciudad de Izamal, del 15 al 20 de agosto de 1921. En la resolución del tema sexto, uno de los postulados rezaba así: "[...] si el capitalista movido por sus iras y ambiciones no

${ }^{47}$ La Revista de Yucatán, Mérida, Yucatán, 11 de julio de 1919.

${ }^{48}$ La Revista de Yucatán, Mérida, Yucatán, 6 de julio de 1919. 
tiene empacho en usar la violencia con los trabajadores, con toda pena y como último recurso tienen la obligación, en casos extremos, de emplear la fuerza bruta contra la fuerza bruta". ${ }^{49}$

En otras palabras, los "sucesos" de Muna se debieron a esa constante concientización de clase que hacían los propagandistas del Partido Socialista y a esa búsqueda de reivindicación social y económica, usando la fuerza si era necesaria, como sucedió en este caso.

Por último quisiera recalcar que los enfrentamientos entre los socialistas y liberales no concluyeron con los "sucesos de 1919", pues hubo en los meses subsiguientes una serie de venganzas de los del "centro" contra los mayas que tomaron parte de la revuelta, traducidas en asesinatos y el incendio de las casas y milpas de estos últimos en los siguientes meses. ${ }^{50}$

No sucedió en Muna otro enfrentamiento de la misma magnitud y resultados que el de 1919, pero sí hubo, en cambio, constantes amenazas por otra parte de los socialistas de tomar la población de nueva cuenta y acabar con los ts'uules. Si no acabaron con ellos, por lo menos fueron perjudicados con el incendio y saqueo de sus establecimientos comerciales, especialmente los hermanos Carrillo.

Quizá el último enfrentamiento de consideración, aunque no equiparable al de 1919, fue durante la rebelión delahuertista a fines de 1923 y principios de 1924, cuando los socialistas apresaron y asesinaron brutalmente a Serapio Cabrera y a otras cinco personas en la cárcel municipal de Muna. En este movimiento perecieron también algunos de los socialistas que habían encabezado los "sucesos de 1919”, entre ellos, Feliciano Chan, Laureano Baas y Teodosio Ortíz, quienes fueron ahorcados en la plaza principal de Muna y sepultados posteriormente fuera del cementerio municipal, como una manera de mostrar el desprecio que la élite sentía por ellos y porque "no eran dignos" de ser enterrados "como cristianos", según lo dictaba la costumbre.

\section{Consideraciones finales}

El Partido Socialista del Sureste y las Ligas de Resistencia fueron organizaciones de obreros y campesinos que llegaron a tener un poder político considerable en la medida que usaban la fuerza para lograr sus fines. Los niveles de organización y de resistencia alcanzados por dichas ligas fueron tales que por ciertos períodos éstas modificaron el orden establecido, desafiaron en una abierta lucha étnica y de clases a las autoridades locales, y a las familias que tradicionalmente habían dominado en los pueblos. Los sucesos de Muna ocurridos en 1919 fueron una

\footnotetext{
${ }^{49}$ Acuerdos del Segundo Congreso Obrero Socialista, celebrado en la ciudad de Izamal, estado de Yucatán, del 15 al 20 de agosto de 1921, véase apéndice de la obra de Paoli y Montalvo (1980: 198-217).

50 AGeY. Fondo Poder Judicial del Estado de Yucatán, Sección: Departamento Judicial de Ticul (6), Serie: Juzgado de $1^{\mathrm{a}}$ Instancia-Ticul, caja 105, exp. 13870. Asunto: Diligencia/Causa seguida por daño en propiedad ajena”, año de 1919; El Correo, Mérida, Yucatán, 7 de julio de 1919.
} 
muestra de lo anterior, más que debido a cuestiones religiosas; el enfrentamiento entre socialistas y liberales de ese año se debió a razones políticas en un intento por reivindicar al indio maya en cuestiones que tenían que ver con el acceso a la tierra, la ocupación de cargos públicos y la distribución equitativa de la riqueza.

Es por eso que, a raíz de los sucesos de esos años, se puede hablar de un antes y un después en la historia de Muna. Después de la agitación vivida durante la revolución, gran parte de la clase acomodada del pueblo abandonó este lugar para irse a vivir a lugares como Mérida y Ticul. A partir de 1930, una tercera parte de la población ya residía en esas ciudades. Hubo gente que regresó cuando las condiciones políticas fueron más favorables y hubo quienes se establecieron definitivamente en los lugares a donde migraron.

De igual manera, otra de las consecuencias de los sucesos fue el hecho de que hicieron su aparición los nuevos ricos, o una clase social emergente, la conformada por los libaneses, los cuales ocuparon algunos de los espacios donde anteriormente la élite local tuvo sus propiedades y comercios.

Asimismo, el socialismo practicado en Yucatán abrió espacios políticos a los mayas en instituciones en las que antes no les daban cabida. Una hojeada a los archivos del ayuntamiento de Muna existentes en el Archivo General del Estado de Yucatán muestra a campesinos mayas ocupando cargos en este cuerpo municipal a partir de los años treinta del siglo xx, conservándose con ligeras variaciones hasta nuestros días.

\section{BIBLIOGRAFÍA}

Ancona, Eligio

1978 Historia de Yucatán desde la época más remota hasta nuestros días (facsímil). Mérida: Ediciones de la Universidad de Yucatán. Tomos IV y V.

Bustillos Carrillo, Antonio

1959 Yucatán al servicio de la patria y de la Revolución. México: Casa Ramírez Editores.

s.f. La Villa de Muna y los mayas del sur de Yucatán. Ensayo Histórico. Mérida: A. Bustillos Carrillo.

Charnay, Desirè

1992 Viaje a Yucatán a fines de 1886. Mérida: Ediciones Dante.

Domínguez, José Luis

1979 "Las luchas campesinas de Yaxcabá, Mérida”. Tesis de Licenciatura en Antropología Social. Mérida, Yucatán: Universidad Autónoma de Yucatán, Escuela de Ciencias Antropológicas.

Gerhard, Peter

1991 La frontera sureste de la Nueva España. México: Universidad Nacional Autónoma de México, Instituto de Investigaciones Históricas. 
Joseph, Gilbert

1992 Revolución desde afuera. Yucatán, México y los Estados Unidos 1880-1924. México: Fondo de Cultura Económica.

Joseph, Gilbert y Allen Wells

1996 "Yucatán. Política de élite e insurgencia rural", Historia regional de la Revolución Mexicana. La provincia entre 1909-1925, Benjamín Thomas y Mark Wasserman (coords.). México: Consejo Nacional para la Cultura y las Artes (Serie Regiones), 139-187.

Mantilla Guiérrez, Jorge

2003 "Política, revolución y poder en Yucatán. Las Ligas de Resistencia, 19171923”. Tesis de Maestría en Etnohistoria. Mérida, Yucatán: Universidad Autónoma de Yucatán, Facultad de Ciencias Antropológicas.

Manzanilla, Anastacio

1921 El bolchevismo criminal de Yucatán. Documentos y apuntes para la historia trágica del estado peninsular. México: Ediciones de "El Hombre Libre".

Martín Díaz, Josefa

2000 Historia de la iglesia presbiteriana en Yucatán. Mérida: Compañía Editorial de la Península, S. A. de C. V.

Medina Un, Martha

1991 “El movimiento popular en Yucatán, 1897-1918”. Tesis de licenciatura en Antropología Social. Mérida: Universidad Autónoma de Yucatán, Facultad de Ciencias Antropológicas.

2010 “Rebelión en el Pu'uk. La lucha por la tierra y el jornal. Yucatán 1911”. Ponencia presentada en el Octavo Congreso Internacional de Mayistas. México, D. F., del 8 al 13 de agosto de 2010.

Negroe Sierra, Genny

2007 "El anticlericalismo en el Yucatán revolucionario", Poder e identidades religiosas en una sociedad en transición, Luis Várguez (ed.). Mérida: Ediciones de la Universidad Autónoma de Yucatán, 63-104.

Paoli Bolio, Francisco J. y Enrique Montalvo Ortega

1980 El socialismo olvidado de Yucatán. Elementos para una reinterpretación de la Revolución Mexicana, $2^{\mathrm{a}}$ ed. México: Siglo XXI Editores.

Quintal Avilés, Ella F. Juan Ramón Bastarrachea, Fidencio Briceño Chel, Martha Medina Un, Teresa Quiñones Vega y Lourdes Rejón Patrón

En prensa "De la costumbre al camino angosto: sistemas normativos y alternativas religiosas en la Península de Yucatán”, Proyecto Etnografía de las Regiones Indígenas de México en el Nuevo Milenio, Elio Masferrer, Ella F. Quintal y Lourdes Báez (eds.). México: Instituto Nacional de Antropología e Historia.

Rodríguez Losa, Salvador

1977 La población de los municipios del Estado de Yucatán, 1900-1970. Mérida: Ediciones del Gobierno del Estado de Yucatán. 
Suárez Castro, María de Guadalupe

2002 "San Francisco es mi intercesor y medianero. Financiamiento de las fiestas patronales en los pueblos de la región pu'uk de la provincia de Yucatán (1580-1781)". Tesis de Licenciatura en Etnohistoria. México: Escuela Nacional de Antropología e Historia.

Stephens, John Lloyd

1984 Viajes a Yucatán, traducción de Justo Sierra O’Reilly. Mérida: Producción Editorial Dante, S. A. (Colección Sureste). 2 Tomos.

\section{Archivos y fuentes documentales}

Archivo General del Estado de Yucatán (AGEY)

1919a Fondo Poder Judicial del Estado de Yucatán, Sección Departamento Judicial de Ticul (06), Serie: Juzgado de $1^{\text {a }}$ Instancia, Ticul (46). "Diligencia/Causa seguida por robo". Alcaldía Municipal de Muna, 1919.

1919b Fondo Poder Judicial del Estado de Yucatán, Sección Departamento Judicial de Ticul (06), Serie: Juzgado de $1^{\text {a }}$ Instancia, Ticul (46), caja 105, vol. 105, exp. 13866. “Diligencia/Causa seguida por robo”. Alcaldía Municipal de Muna, 1919.

\section{Hemerografía}

Bastarrachea Buenfil, Anatolio

1919 "El Partido Socialista protesta contra los crímenes desarrollados en Muna", La Revista de Yucatán, Mérida, Yucatán, 3 de julio de 1919.

Blanco Rosado, Asunción

1919 "Remitido", La Revista de Yucatán, Mérida, Yucatán, 3 de julio de 1919.

Cabrera, Serapio, Enrique Cáceres, Manuel y Sóstenes Carrillo y Delio Lara

1919 "Protesta", La Revista de Yucatán, Mérida, Yucatán, 6 de julio de 1919.

Carrillo Rodríguez, Manuel

1919a "De Muna. Un escándalo contra el alcalde municipal”. La Revista de Yucatán, Mérida, Yucatán, 22 de marzo de 1919.

1919b "Rumbosa fiesta en el barrio de San Bernardo de la Villa de Muna", La Revista de Yucatán, Mérida, Yucatán, 25 de mayo de 1919.

"Cómo explica D. Anatolio Bastarrachea Buenfil los sucesos de Muna a la prensa metropolitana"

1919 El Correo, Mérida, Yucatán, 25 de julio de 1919.

"Continuación de las últimas noticias de los sucesos de Muna tomadas en la misma población por nuestro enviado especial"

1919 El Correo, Mérida, Yucatán, 8 de julio de 1919.

Chin May, Arturo

2000 "Breve reseña histórica de la iglesia presbiteriana", iPor esto!, Sección Yucatán, Ticul, ediciones de los días 24, 29, 31 de mayo y 8 de junio de 2000. 
Diario de los debates de la Cámara de Diputados del Congreso de los Estados Unidos Mexicanos. 1919 Sesión efectuada el día 12 de julio de 1919. Año 1, Período extraordinario XXVIII legislatura, Tomo II, No. 64, en línea: <http://cronica.diputados. gob.mx/DDebates/28/1 er/Extra/19190712.html > . [Consultado en agosto de 2010.]

"De Muna”

1919 La Revista de Yucatán, Mérida, Yucatán, 21 de mayo de 1919.

"De última hora"

1919 La Razón, Mérida, Yucatán, 7 de julio de 1919.

"Ecos de los sangrientos sucesos de Muna"

1919 La Revista de Yucatán, Mérida, Yucatán, 5 de agosto de 1919.

"El retorno de los deportados por los sucesos de Muna"

1919 El Correo, Mérida, Yucatán, 24 de julio de 1919.

“La Razón”

1919 La Razón, Mérida, Yucatán, 31 de enero de 1919.

"La 'San Bartolomé' de anteanoche en la villa de Muna"

1919 La Revista de Yucatán, Mérida, Yucatán, 29 de junio de 1919.

"Los acusados por causa de las matanzas de Muna llegaron y pasaron para México a pesar del amparo que llevaron"

1919 El Correo, Mérida, Yucatán, 18 de julio de 1919.

"Los crímenes de Muna son los frutos del árbol sembrado por las Ligas de Resistencia" 1919 El Correo, Mérida, Yucatán, 7 de julio de 1919.

"Los sucesos de Muna"

1919 El Correo, Mérida, Yucatán, 13 de agosto de 1919.

"Los sucesos de Muna"

1919 El Correo, Mérida, Yucatán, 11 de agosto de 1919.

"Mas sobre los salvajes sucesos de Muna"

1919 La Revista de Yucatán, Mérida, Yucatán, 30 de junio de 1919.

"Mas sobre los sucesos de Muna"

1919 La Revista de Yucatán, Mérida, Yucatán, 10 de julio de 1919.

"Notas socialistas"

1919 La Revista de Yucatán, Mérida, Yucatán, 13 de marzo de 1919.

"Presos de los sucesos de Muna embarcados para Veracruz"

1919 La Revista de Yucatán, Mérida, Yucatán, 6 de julio de 1919. 
"Últimas noticias de los sucesos de Muna tomadas en la misma población por nuestro enviado especial"

1919 El Correo, Mérida, Yucatán, 7 de julio de 1919.

"Un nuevo mentís a los que dicen a los que dicen que no hay justicia en el estado. Quedan en libertad 39 de los detenidos por los sangrientos sucesos de Muna"

1919 El Correo, Mérida, Yucatán, 5 de agosto de 1919.

"Una compacta multitud de vecinos de Muna ante nuestras oficinas protesta contra Don Felipe Carrillo Puerto"

1919 La Revista de Yucatán, Mérida, Yucatán, 5 de julio de 1919.

"42 presos de Muna puestos en libertad"

1919 La Revista de Yucatán, Mérida, Yucatán, 11 de julio de 1919. 
